\section{THE DEATH FROM CHLORAL.}

To the Editor of THE LaNCET.

SIR,-I shall feel obliged if you will allow me to make a few remarks on the unfortunate occurrence that recently took place in my establishment at Balham, but before doing 60 I must point out the errors of the reporters which have been circulating in the daily papers :-

1st. Neitber I nor any of the witnesses at the inquest made use of the term "dipsomaniac," the reporters having substituted it for the word I actually used, which was " intemperate."

2nd. I said, "lately senior surgeon, and now consulting surgeon to the Westminster Hospital," and not senior consulting surgeon.

3rd. I never, as reported, prescribe a given quantity of chloral every night, but only such a dose as the condition of the patient seems to require.

4th. I did not say 80 grains might be given with impunity at one time, and at another 20 might prove fatal; but I did say something equivalent to this, substituting 60 and 30 grains for 80 and 20 grains.

5th. It did not transpire, as stated by The Times, that a larger dose had been given on the fatal morning than on any previous occasion.

Lastly. I was not in the habit of giving the chloral in five ounces of water, as reported, but in three, and the last time it was made up was the only occasion in which five ounces were given.

The statement of the attendant that the decased had said, how very careless I was, must have had reference either to the quantity or quality of the mixture; as regards the former, I am in the habit of giving from 20 to 60 minims of the solution of chloral, which contains one grain of the salt to one minim of water, as prepared by the General Apothecaries' Company, in an ounce and a half of water, and, therefore, in the two doses I put three ounces; but the nurse, who made up that which the patient so much complained of, had put five ounces of water instead of three. As regards quality, his remark might have had reference to the varying strength of the draught. On one occasion I reduced the dose of chloral to 35 grains, but the patient passed a wretched night, and I was obliged to raise it again till 50 grains seemed to be the minimum quantity required to produce the desired effect. This may seem, and no doubt is, a large and possibly might be a poisonous dose to a temperate man, as half an ounce of opium would be; but to a regular chloral taker, or opium eater we know it is not so. My rule is to give the least quantity that will procure sleep, and if that does not ensue within two hours, I give another dose or half dose, according to circumstances. In the case of a confirmed brandy drinker and morphia taker, I prescribed 60 grains of chloral, and it was not till three such doses had been taken, or 180 grains, that sleep followed. In another case, one of delirium tremens, where the gentleman had had no sleep for three nights and was worn out, 20 grains quickly produced the desired result, and he slept quietly for twelve hours continuously, then awoke to relieve himself and take nourishment, and again fell asleep for nine hours, when he awoke well.

I have found that as the alcohol is got rid of out of the system, so the quantity of chloral required to proaure sleep is less, and in the majority of cases that have come under my treatment it has been dispensed with altogether within a week of the patient's admission. The injurious practice of giving alcohol in these cases, with the view of letting them down gently, as it is called, and its retardative effect on recovery, could not have been better illustrated than in this case, which was not worse, or even so bad as some have had under my care; but my treatment was counter. acted from the first by the importunities and threats of the patient, and by the too-yielding nature of my attend ants. In cases of this description the greatest kindness is severity.

The history of the case is briefly as follows :-Mr. had been given to intemperance since eighteen years of age, and latterly had been also a regular chloral drinker. He told me his usual dose was 40 grains, with 20 grains of bromide of potash; but how often he took this he did not say. My object and intention were to cut off both the alcohol and chloral, the former at once, the latter by degrees, as sleep was absolutely necessary. I fonnd out that, moved by his entreaties and assurances that as be was a medical man himself he knew what was best for him, and as a lesser evil than his going out to procure drink, my attendants, against my orders, gave him from time to time small quantities of whisky. The chloral, of which I never ordered a stated dose to any one, bad on all but two occasions previously been given by myself the largest dose the patient had taken having been 60 grains, which was on the night of his admission. On the night in which it proved fatal $I$ had not prescribed any, having expostulated strongly with him on the subject the day before, and told him it must be absolutely cut off. I had not, however, forbidden my attendants to give it, becange on no previous occasion had it been given without my direct sanction; but they, relying on precedent and with disastrous faith in the patient's own medical knowledge, administered that last dose, which from subsequent, analysis has been found to contain less than 50 grains. My invariable order to the attendant is to allow two bours to elapse before a second dose is given; but from investigations made subsequent to the inquest it would appear that the first dose could not have been taken before half-past 11 , so that the portion of the second which was used must have been taken about an hour after it, death having ensued some time before 1 o'clock. Notwithstanding the mistaken kindness of my attendants in giving the decensed a little alcohol indoors to prevent his going out and getting much, he nevertheless did go out and procured both drink and chloral. It is greatly to be regretted that there is no legal power to prevent these cases of self-destruction. Could such power have been exercised, this fine man, who was beloved by all and who possessed both physical and mental gifts which are the portion of few, might have been enabled to overcome this enemy and been an ornament to his profession and society.

Your obedient servant,

Balham.hill House, May 8th, 1877. CARsten HoLTHoUsE.

\section{DENTAL REFORM.}

To the Editor of THE LANCET.

Sin,-Mr. Cartwright has spoken for me on several occasions, and MTr. Coleman has condemned my deeds in your last issue. In return I ask you to allow me to speak for myself. Mr. Cartwright complains that your printer, by a press error in the use of inverted commas, placed wrongly to my account a resolution with the wording of which he did not wish to charge me. Printers seem to be a very sorry set of blunderers; for the printer of the British Medical Association Journal has, with singular exactness, committed the same error in the use of commas. Mr. Cartwright evidently fails to see the difference between a law which would interfere with existing practitioners and one which would restrict its operation to those persons who bave yet to enter upon their professional studies: for in his letter dated May 2nd he persists in regarding Resolution 5, quoted (not quite correctly) at the end of Mr. Coleman's letter, as an attack upon existing practitioners. I think Mr. Cartwright would understand the difference between a law which proposed to deprive him of a life-lease, and one which declined to renew the lease to an unborn suecessor without alteration of terms, and this is all the Dental Reform Association proposes shall be done in respect to professional titles and registration.

Mr. Coleman attaches great importance to what he calls the legal rights of the Medical Corporation in the use of the designation surgeon-dentist, \&c. He may be justly challenged to produce a proof of such rights. I do not think he will find the mention of any special branch of surgery in the charters of incorporation, excepting in those granted recently to the College of Surgeons, of which the Dental cbarter is the latest, and bears the date 1859. But the case of Mr. Gould proved conclusively that the Medical Corporations represented by the Medical Council have no legal authority or right in the use of the title of surgeon-dentist. \&c. Any person not legally qualified may be fined for stgling h $1 \mathrm{~m}$ self a surgeon; but no person can be punished for assuming the title of surgeon-dentist. If the right by usage be claimed, then it may be shown that the rast majority (ten to one) of 
those who have used the title are not members of any medical corporation.

But dental surgery, as is now known, is, in fact, a new acience - $a$ new branch of the healing art,-Developed within the present century, mostly within the last half-century, and most rapidly within the last five-and-twenty years, and it could not be rightly dealt with by laws enacted before it came into existence. The acknowledged legislative want was met in the Dental charter granted to the College of Surgeons, and what is now needed to perfect the powers is the addition of a suitable registration. The cry of "vested interests" may be raised against any change of law however needful, or, as in the present case, against the introduction of law in the place of lawlessness, against the substitution of rule for disorder.

The question of expediency and liberality stands below justice. If special training makes the best practitioner, the advantage should be secured for the use of the public, for whose assistance dentists exist; and it does not exceed the purposes of justice that the trained should be distinguished by title from the untrained special practitioner.

But these contentions respecting title and registration are rather beside the mark, and serve only to mask the much more important question of special education. Special training is either a necessity for the dental surgeon or it is a troublesome superfluity. The Association of Qualified Surgeons practising Dental Surgery wholly ignores the dental qualification by excluding from its membership those practitioners who possess the dental licentiateship only; and in a set of resolutions lately forwarded to the College of Surgeons, say indirectly, but still very plainly, that the special education is quite needless. This Association urges that the possession of the licentiateship shall not of itself aualify a person to teach in a dental school, or to hold a hospital appointment, but that the possession of a registerable surgical qualification shall in itself fully qualify the holder for either office. Now, if the special education, of which the licentiateship is but the authentic testimony, is needless for the teacher of dental surgery or for a hospital dentist, how, in the name of common sense, can it be urged that a special training is necessary for the practitioner. In other words, the Association denies, by its rules and resolutions, the necessity of special education; and indirectly asserts that the dental curriculum and licentiateship are but troublesome superfluities.

Mr. Cartwright and Mr. Coleman have for many years been teachers in the London School of Dental Surgery. They have received the fees of students and rendered themselves responsible for the special education of their pupils, and their change of opinion has been sudden and unexpected. The one is the president, the other the treasurer, of this hostile Association. It is difficult to estimate the numerical strength of the party of which they are leaders, for, although the resolution sent to the College was backed by thirty-eight dental practitioners, the signatures were in many cases appended without consulting the owners, and it is known that many whose names were used are strong supporters of special education. To the counter memorial in favour of the licentiateship the names of 259 qualified dental practitioners were appended with their individual assent.

A consideration of the foregoing facts will afford a sufficient explanation of the opposition given to the proceedings of the Dental Reform Association by Mr. Cartwright and Mr. Coleman. They may reasonably object to the registration of a qualification to the existence of which they are opposed, and on this ground only can it be contended without insult to the client that the surgeon without special training would desire to assume the title of surgeondentist.

If a perfectly fitting education, obtained at the hands of the College of Surgeons, tends to a separation of dental from general surgery, the fears of another correspondent may be realised; but it would not be difficult to prove that the tendency is altogether in the opposite direction. Identity is not a necessity of affiliation or of equality. But come what may, dental surgery must be specially taught and practised, and if the teaching fail here, the practice should, in common honesty, be abandoned in favour of those who are taught elsewhere.

The public has a right to exact competence in dental practitioners, and skilfulness can be gained only by early training under skilful teachers. The principles of music may be learned at any age; but to become a skilful per. former the student must, in his youth, patiently practise under efficient teachers; and so it is witb dental surgery.

The skilful in all occupations, great and small, have a solid pleasure in the exercise of their powers, and are justly proud of their calling. True dignity is consistent only with truthfulness in its highest sense, and amongst professional men he only is truthful who is master of his professed subject. Dental surgery is a public necessity and honourable to its re. presentatives if honourably followed. There may be shame somewhere; but certainly not in the name of dentist, or in the subject of dental surgery.

Caterham Valley, May 8, 1877. Yours faithfully,

To the Editor of The LaNCET.

Srr,-I shall feel obliged if you will insert the enclosed copy of a letter sent to the Secretary of the Dental Reform Committee.

Bath, May 7th, 1877.

Your very truly,

Chartes Gaine.

[Copy.]

8, Edgar-buildings, Bath, May 7th, 1877.

Dear Str,-I have just read in The LanceT some of the absurd clauses proposed by the Dental Reform Com. mittee, and as I (as a member of that body) have been no party to the framing of such a code, must request you will be good enough to remove my name from the list of members.

J. S. Turner, Esq.

I am, dear Sir, yours faithfully, Charlins Gatne.

\section{UNUNITED TENDO ACHILLIS.}

To the Editor of The LaNCET.

SiR,-In your number of last Saturday you were good enough to insert the note of a case of Ununited Tendo Achillis treated successfully by me.

Since that note was written my attention has been directed to a case in which Dr. Little ${ }^{1}$ performed a subcutaneous operation with an excellent result, after non-union of the same tendon. In Dr. Little's case the non-union was the result of a subcutaneous division of the tendon, and therefore it differed somewhat in its nature from mine. Whether or not Dr. Little's operation will prove successful in a case of division of the tendon by external wound has still to be proved; but should I meet with another ease such as I reported in your last number, I will certainly try this proceeding in the first instance, as it is more simple in every way than the one I myself adopted.

I remain, Sir, yours faithfully,

Charlotte-square, Edinburgh. Thomas annandale.

\section{TRANSFUSION}

To the Editor of The LANCET.

SIR,-Dr. Roussel's letter in your number, May 5th, renders it necessary for me to state that I have not yet altered my transfusion apparatus, and that $I$ have no intention of adopting and affixing to $\mathrm{my}$ instrument the parts of his transfuser which he claims to have invented.

I am, Sir, \&c.,

Upper Wimpole-street, W., May 8th, 1877. J. H. AvELING, M.D,

\section{MANCHESTER.}

(Erom our own Correspondent.)

THe Infirmary war still continues to rage, one party en. deavouring to make the expenditure appear excessive, the other striving to show that the present management and economy are convertible terms. To this end statistics, as usual, are made to play their chameleon part. At a meeting of the weekly board on Monday, April 30th, Mr. Hulse stated that the average expenditure for the past three years was $\$ 21,4195 s .9 d$; the number of beds for the same period

I On the Deformities of the Human Frame, p. 166 . 